\title{
An Anatomical Study of the Aortic Arch Variations
}

\author{
Haifa A. Alsaif, MSc and Wafaa S. Ramadan', MD \\ Department of Medical Laboratory, Faculty of Applied Medical Sciences, \\ Taif University, Taif, Saudi Arabia \\ ${ }^{1}$ Department of Anatomy, Faculty of Medicine, \\ King Abdulaziz University, Jeddah, Saudi Arabia \\ wsaadeldin@hotmail.com
}

\begin{abstract}
Complications of an open surgery on the aortic arch include ischemic problems, which can be caused by unrecognized variation of its vascular anatomy. The aim of this study was to determine the anatomical basis needed for its surgical procedures. Thirty adult human preserved cadavers, six separate hearts with the aortic arches, images of computerized tomography and aortic angiography were used. The branching pattern of the aortic arch was studied; diameters of its branches and the distance from their origin to the mid-vertebrae line were measured. In $75 \%$ of the cases, the brachiocephalic trunk, left common carotid and left subclavian artery originated independently. $66.66 \%$ of the remaining variants had two branches, the left subclavian artery and a common trunk which incorporated the brachiocephalic trunk and left common carotid. In $22.2 \%$, the arch had four branches which was the left vertebral artery. In $11 \%$, the left vertebral artery arose with the left subclavian artery from a common trunk. There was a significant correlation between the diameters of brachiocephalic trunk and left subclavian artery. A significant strong positive correlation between the distances from the origins of left common carotid and left subclavian artery from the mid vertebrae line was found. The results in this study provide accurate information considered vital for vascular surgery.
\end{abstract}

Keywords: Variation, Aortic arch, Mid-vertebrae line.

Correspondence \& reprint request to: $\quad$ Dr. Wafaa Ramadan P.O. Box 80205, Jeddah 21589, Saudi Arabia

Accepted for publication: 27 March 2010. Received: 15 February 2010. 


\section{Introduction}

The most common branching pattern of the aortic arch (AA) in humans comprises of three great vessels; first, the brachiocephalic trunk (BT), then the left common carotid artery (LC) and finally the subclavian artery (LS). This pattern occurs in $65-80 \%$ of the cases ${ }^{[1]}$.

The final configuration of the AA and its branches is probably related to the associated "migration" and "merging" of the branches, together with the different growth rates in the various arteries ${ }^{[2]}$. The AA anomalies are also associated with chromosome $22 \mathrm{q} 11$ deletion ${ }^{[3]}$.

Different variations concerning the origin and number of the branching pattern of the AA as an increase or decrease in the number of branches or common origin of its major branches were considered as normal variants ${ }^{[4]}$. The anatomic and morphologic variations of the AA and its branches are significant for diagnostic and surgical procedures in the thorax and neck ${ }^{[5]}$.

Despite accurate preoperative assessment and adequate preparations, unexpected and sometimes unsuccessful situations can occur during vascular surgery. Complication of open surgery of the AA include ischemic problems which can be caused by unrecognized variation of the vascular anatomy ${ }^{[6]}$.

The presence of anomalous arch vessels has considerable impact on AA reconstruction techniques and cerebral protection methods when the separated graft technique is adopted to perform total arch replacement. Some anomalous aortic branches, as the left vertebral artery (LV), are difficult to diagnose preoperatively as it is often obscured by other larger arch branches, making its preoperative detection considerably more difficult. They are most often discovered intra-operatively, hence it is necessary to take special precaution while the arch branches are dissected and exposed ${ }^{[7] \text {. }}$

Diagnosis of a cerebrovascular injury may be based on a wrong assumption that the vertebral artery (VA) is occluded by simply lying outside the region of interest during noninvasive studies, such as computerized tomography angiography (CTA), Magnetic Resonance Angiography (MRA), or Doppler sonography ${ }^{[8]}$.

Therefore, it appears that the true value of detecting anomalous arch vessels is in the diagnostic gain before planning an AA surgery or endovascular interventions. 
In performing endovascular surgery, the most common technique is to puncture the femoral artery and advance a catheter towards the AA through the abdominal aorta, as well as the major branches originating from the AA. Despite the improvement of catheter quality and the rapid development of fluoroscopic imaging, this usual technique may be very difficult to perform in some cases due to the anatomical variations of the $\mathrm{AA}$ and its major branches ${ }^{[9]}$. Also, serious complications may develop due to these procedures ${ }^{[10]}$. Thus, obtaining enough knowledge of the anatomic variations of the AA before inserting a catheter into the blood vessels is essential in order to avoid injuring neighboring structures.

\section{Aim of Study}

The aortic arch is a challenging site for endovascular repair. The aim of the present work was to study the branching pattern of the aortic arch, the diameters of its branches and the distance from their origin to the mid-vertebrae line. This study would provide an anatomical basis to assist surgeons in performing safe vascular surgery involving the AA, and its branches as cases in which stenting are used as an adjunct to balloon angioplasty for the treatment of both stenotic and occlusive lesions of the supra aortic trunks.

\section{Materials and Methods}

This study was performed on thirty adult human preserved cadavers and six pre-dissected separate hearts with the aortic arches en-bloc. They were obtained from the Department of Anatomy, Faculty of Medicine, King Abdulaziz University after the approval of the Ethical Committee. The sex and age of the cadavers were not to be assessed in this study.

The thirty adult human cadavers included specimens not dissected, subjected to previous dissection, or previously injected with colored latex. Dissection of the superior mediastinum was done routinely in cadavers in whom the thoracic cavity was not opened. A transverse incision through the manubrium sterni, just below the level of the first rib was done. It was extended posteriorly through the first intercostal space. The ribs from 2-9 were cut at costochondral junction. The sternum was turned on to the upper part of the abdominal wall. The fat tissue and the pericardium covering the ascending aorta and the great vessels were removed. The right and left brachiocephalic veins were gently cut ${ }^{[11]}$. 
In cadavers subjected to previous dissection, the abdominal and the thoracic cavities were opened and the lungs were removed. Some cadavers were injected previously with colored latex for the study of some vessels.

The following morphological parameters have been recorded:

- Examination of the branching pattern of the AA major branches.

- Brachiocephalic trunk (BT), the left common carotid artery (LC), and the left subclavian artery (LS).

- Identifying additional arteries originating from the aortic arch.

- Measuring the distance between the mid-vertebrae line, and the branches originating from the $\operatorname{arch}^{[9]}$. This was done only in the 30 cadavers (Fig.1).

- Measuring the diameter of all branches at the site of their origin from the arch. Measurements were done using a Vernier caliper, accuracy $0.01 \mathrm{~mm}$. (Fig. 2).

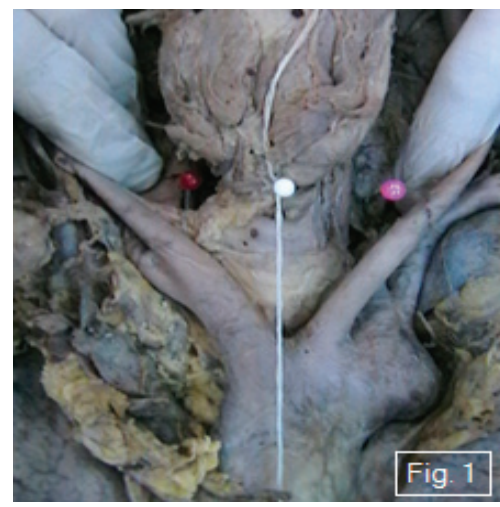

Fig. 1. A photograph of a dissected aortic arch shows the midvertebrae line.

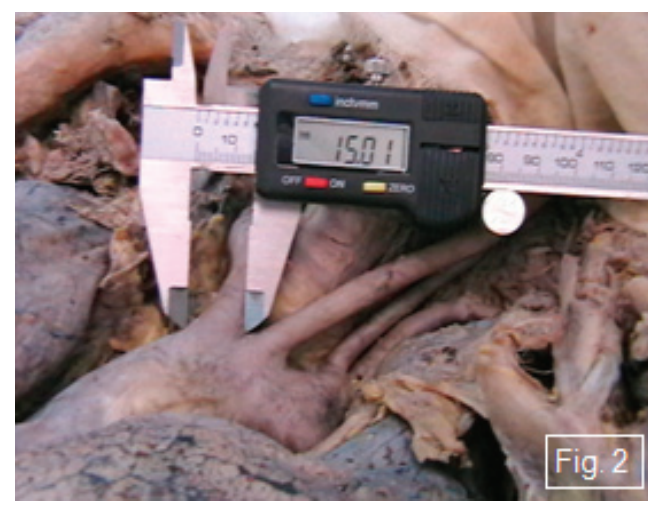

Fig. 2. A photograph of the aortic arch shows the Verneir caliper used in measurement.

Additionally, photographs were taken using digital camera (Panasonic VDR-D150).

The statistical analysis of collected data using the SPSS program version 12 was performed and $\mathrm{p}<0.05$ was considered to be a significant difference.

The study was assisted by computerized tomography images (Enhanced CT scan images), aortic angiography from different patients 
with different purposes like chest and neck CT scan to evaluate neck masses; or to rule out pulmonary embolism etc., which revealed these variations. The CTs were obtained from the Radio-diagnostic and Medical Imaging Department, King Fahd Armed Forces Hospital in Jeddah. Patients' names and their file numbers were not shown in the images obtained abiding by the ethical rules of the hospital. The sex and age of the randomly chosen patient were not considered or assessed as in the preserved cadaveric study.

CTA protocol was done by sensation $64 \mathrm{CT}$ scanner. The procedure was enhanced by IV injection of about $140 \mathrm{ml}$ of iodinating contrast material in the left antecubital vein. The rate of injection was 3-4 $\mathrm{ml} / \mathrm{second}$. Scan started from the $10^{\text {th }}$ thoracic vertebra till the base of the skull.

\section{Results}

In this study the aorta commenced at the upper part of the left ventricle. After ascending for a short distance, it arched backwards and to the left, over the root of the left lung. Then, it descended on the left side of the thoracic part of the vertebral column. It was related anteriorly to the left brachiocephalic vein crossing its upper part. The left surface of the arch was crossed by the left phrenic nerve and the left vagus nerve, which gave off its recurrent laryngeal branch hooking below the vessel and then passed upward on its right side. The right posterolateral surface was related to trachea, and the vertebral column. Inferior to the arch, the bifurcation of the pulmonary trunk was identified (Fig. 3 and 4).

In this study the most common AA branching pattern was found in 27 (75\%) of 36 specimens. In this pattern the three major branches; BT, LC, and LS originated independently from the arch of the aorta (Fig. 4).

The origin of the BT from the AA deviated by a mean of $9.33 \pm 4.66$ $\mathrm{mm}$ to the right of the mid-vertebrae line (ranged from 0.00 to $20.00 \mathrm{~mm}$ ) (Table 1).

The mean diameter of the BT was $17.97 \pm 3.85 \mathrm{~mm}$. The length of the diameter ranged from 10.00 to $25.00 \mathrm{~mm}$ (Fig. 5, 6 and Table 2). The LC originating from the AA deviated by an average of $9.90 \pm 5.28 \mathrm{~mm}$ to the left of the mid vertebrae line. It ranged from 1.00 to $20.00 \mathrm{~mm}$ (Table 
1). The mean diameter of LC was $9.77 \pm 1.91 \mathrm{~mm}$ (ranged from of 6.00 to $15.00 \mathrm{~mm}$.) (Fig.7, 8 and Table 2).

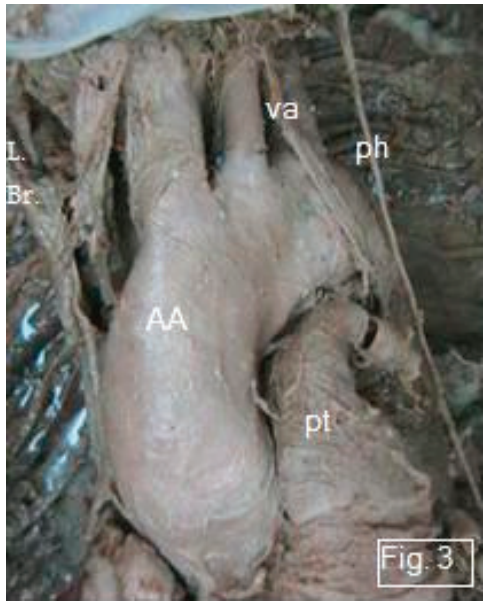

Fig. 3. A photograph of the aortic arch (AA) showing its relations. The left phrenic (ph) and left vagus (va) nerves cross the left surface of the arch. Pt: pulmonary trunk. L.Br: reflected left brachiocephalic vein.

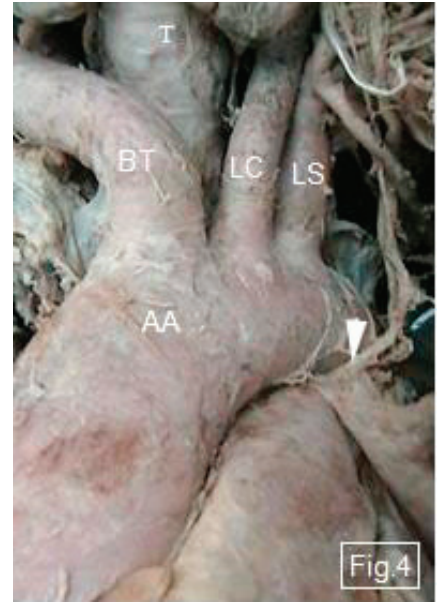

Fig. 4. A photograph of the aortic $\operatorname{arch}(\mathrm{AA})$ showing its common branching pattern. The three major branches arise independently from the arch. BT: Brachiocephalic trunk. LC: left common carotid artery. LS: left subclavian artery. T: trachea. (head arrow): Left recurrent laryngeal nerve.

Table 1. Distance from the mid-vertebrae line to the origin of the major branches of the aortic arch (in mm).

\begin{tabular}{c|c|c|c|c|c|c}
\hline & N & Mean & SD & Minimum & Maximum & Range \\
\hline BT & 30 & 9.33 & -4.66 & .00 & 20.00 & 20.00 \\
\hline LC & 30 & 9.90 & +5.28 & 1.00 & 20.00 & 19.00 \\
\hline LS & 30 & 25.73 & +7.57 & 12.00 & 40.00 & 28.00 \\
\hline
\end{tabular}

BT: Distance from the mid-vertebrae line to the origin of the brachiocephalic trunk; LC: Distance from the mid-vertebrae line to the origin of the left common carotid artery; LS: Distance from the mid-vertebrae line to the origin of the left subclavian artery, SD: standard deviation, negative (-): right side based on the mid-vertebral, line positive (+): left side based on the mid-vertebral line.

The third branch LS deviated to the left from the mid-vertebrae line by a mean of $25.73 \pm 7.57 \mathrm{~mm}$ (ranged from 12.00 to $40.00 \mathrm{~mm}$ ) Table 1 . Its mean diameter was of $14.33 \pm 3.09 \mathrm{~mm}$ (ranged from 7.00 to $2.00 \mathrm{~mm}$ ) (Fig. 9, 10 and Table 2). There was also significant positive correlation $(\mathrm{r}=.467)$ between the diameters of BT and LS at $(\alpha=0.05)$ (Table 3). 
A significant negative correlation $(r=-.496)$ was found between the distance from the origin of BT to the mid vertebrae line and that of LC. However, the distance between the origin of BT to the mid vertebrae line and that of LS showed a weak negative correlation $(r=-.431)$. There was a significant strong positive correlation between the distance LC from the mid vertebrae line and that of LS $(r=.708)$ (Table 3$)$. The variations in AA regarding its branching pattern were also observed in the remaining nine specimens $(25 \%)$.

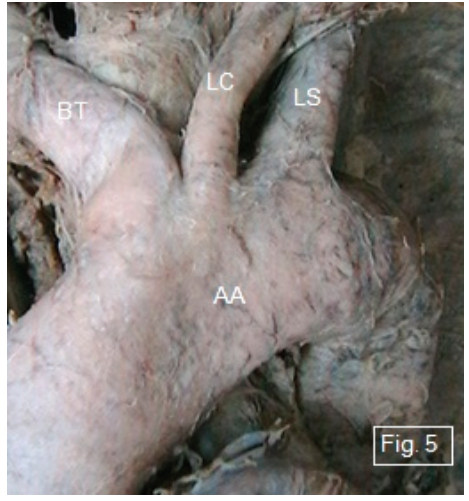

Fig. 5. A photograph of the aortic arch (AA) shows the brachiocephalic trunk (BT) with the widest diameter. LC: left common carotid artery. LS: left subclavian artery.

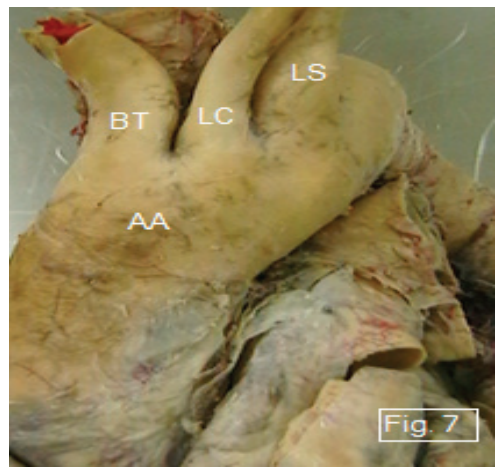

Fig. 7. A photograph of the aortic arch (AA) shows the left common carotid artery (LC) with the widest diameter. BT: brachiocephalic trunk. LS: left subclavian artery.

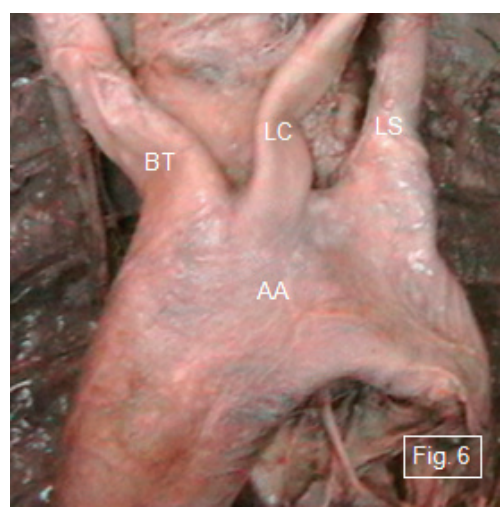

Fig. 6. A photograph of the aortic arch (AA) shows the brachiocephalic trunk (BT) having the smallest diameter. LC: left common carotid artery. LS: left subclavian artery.

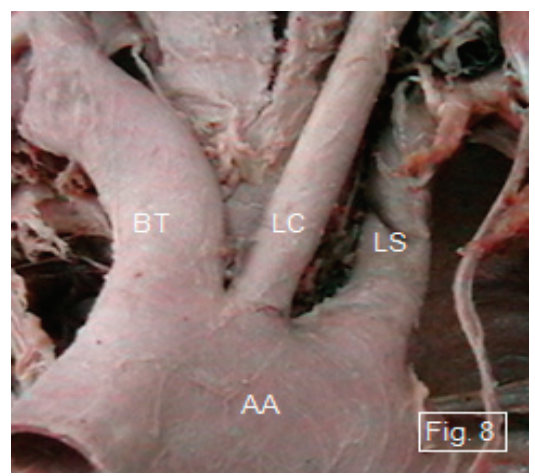

Fig. 8. A photograph of the aortic arch (AA) shows the left common carotid artery (LC) having the smallest diameter. BT: brachiocephalic trunk. LS: left subclavian artery. 
Table 2. Diameters of the three major branches of the aortic arch (in $\mathbf{m m}$ ).

\begin{tabular}{l|c|c|c|c|c|c}
\hline & N & Mean & SD & Minimum & Maximum & Range \\
\hline BT & 36 & 17.97 & 3.85 & 10.00 & 25.00 & 5.00 \\
\hline LC & 36 & 9.77 & 1.91 & 6.00 & 15.00 & 9.00 \\
\hline LS & 36 & 14.33 & 3.09 & 7.00 & 20.00 & 13.00 \\
\hline
\end{tabular}

SD: standard deviation, BT: brachiocephalic trunk, LC: left common carotid artery,

LS: left subclavian artery.

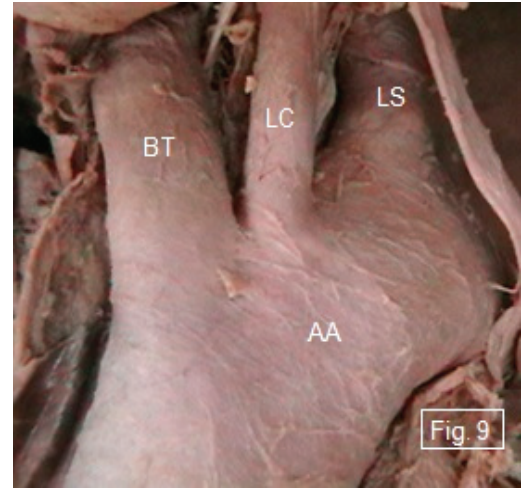

Fig. 9. A photograph of the aortic arch (AA) showing the left subclavian artery (LS) with the widest diameter. BT: brachiocephalic trunk. LC: left common carotid artery.

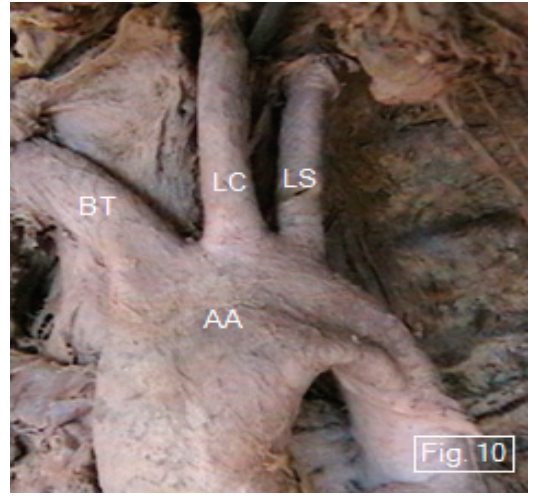

Fig. 10. A photograph of the aortic arch (AA) showing the left subclavian artery (LS) with the smallest diameter. BT: brachiocephalic trunk. LC: left common carotid artery.

In the present study, a common origin of these major vessels was noted. The AA in six specimens of the above group $(66.66 \%)$ had only 2 great branches. They originated from the upper convex surface of the aortic arch. The first was a common trunk, which incorporated the BT and the LC. The second was the LS, which arose independently distal to the origin of the common trunk (Fig. 11). The shape, length, diameter of the trunks and their length away from the mid-vertebrae line varied considerably.

The mean length of the trunk from its origin to the level of bifurcation into BT and the LC was $15.00 \pm 5.86$ (ranged from 10.00 to $26.00 \mathrm{~mm}$ ) (Fig. 12, 13 and Table 4). The mean diameter of the trunk was $30.33 \pm 5.16 \mathrm{~mm}$. (ranged from 25.00 to $40.00 \mathrm{~mm}$ ) (Fig. 12, 14 and Table 4). The mean distance between the origin of the common trunk and the mid-vertebrae line, was of $13.83 \pm 3.97 \mathrm{~mm}$, (ranged from 9.00 to $20.00 \mathrm{~mm}$ ) (Table 4). 
Table 3. The correlations between distances from the mid-vertebrae line and diameters of the three major branches.

\begin{tabular}{|c|c|c|c|c|c|c|c|}
\hline & & $\begin{array}{l}\text { Distance } \\
\text { of (BT) } \\
\text { from mid } \\
\text { vertebral } \\
\text { line }\end{array}$ & $\begin{array}{l}\text { Distance of } \\
\text { (LC) from } \\
\text { mid } \\
\text { vertebral } \\
\text { line }\end{array}$ & $\begin{array}{l}\text { Distance of } \\
\text { (LS) from } \\
\text { mid } \\
\text { vertebral } \\
\text { line }\end{array}$ & $\begin{array}{c}\text { Diameter of } \\
\text { (BT) }\end{array}$ & $\begin{array}{l}\text { Diameter } \\
\text { of (LC) }\end{array}$ & $\begin{array}{l}\text { Diameter } \\
\text { of (LS) }\end{array}$ \\
\hline $\begin{array}{l}\text { Distance of } \\
\text { (BT) from mid } \\
\text { vertebral line }\end{array}$ & $\begin{array}{l}\text { Pearson } \\
\text { Correlation }\end{array}$ & & $-.496^{*}$ & $-.431^{*}$ & -.097 & .043 & -.146 \\
\hline $\begin{array}{l}\text { Distance of } \\
\text { (LC) from mid } \\
\text { vertebral line }\end{array}$ & $\begin{array}{l}\text { Pearson } \\
\text { Correlation }\end{array}$ & $-.496^{\star}$ & & $.708^{*}$ & .115 & -.081 & .019 \\
\hline $\begin{array}{l}\text { Distance of } \\
\text { (LS) from mid } \\
\text { vertebral line }\end{array}$ & $\begin{array}{l}\text { Pearson } \\
\text { Correlation }\end{array}$ & $-.431^{*}$ & $.708^{*}$ & & -.139 & -.316 & .047 \\
\hline $\begin{array}{l}\text { Diameter of } \\
\text { (BT) }\end{array}$ & $\begin{array}{l}\text { Pearson } \\
\text { Correlation }\end{array}$ & -.097 & .115 & -.139 & & .137 & $.467^{*}$ \\
\hline $\begin{array}{l}\text { Diameter of } \\
\text { (LC) }\end{array}$ & $\begin{array}{l}\text { Pearson } \\
\text { Correlation }\end{array}$ & .043 & -.081 & -.316 & .137 & & .270 \\
\hline $\begin{array}{l}\text { Diameter of } \\
\text { (LS) }\end{array}$ & $\begin{array}{l}\text { Pearson } \\
\text { Correlation }\end{array}$ & -.146 & .019 & .047 & $.467^{*}$ & .270 & \\
\hline
\end{tabular}

Correlations

* Correlation is significant at the 0.05 level.

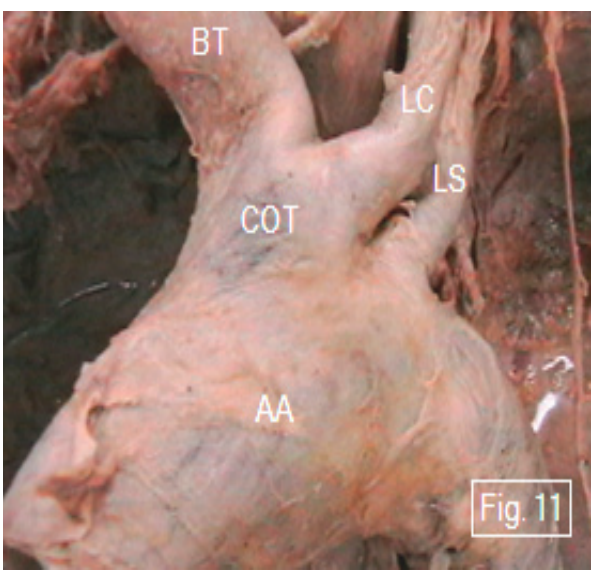

Fig. 11. A photograph of the aortic arch (AA) showing a common trunk (COT) of brachiocephalic trunk (BT) and the left common carotid artery (LC). The left subclavian artery (LS) originates from the arch distal to the (COT).

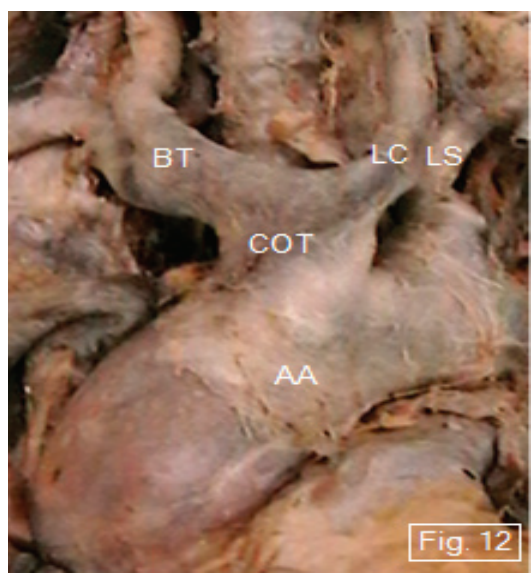

Fig. 12. A photograph of the aortic Arch (AA) showing the common trunk (COT) having the longest and widest measurements. The brachiocephalic trunk (BT) and the left common carotid (LC) arise from the (COT). The left subclavian artery (LS) arises independently from the arch. 


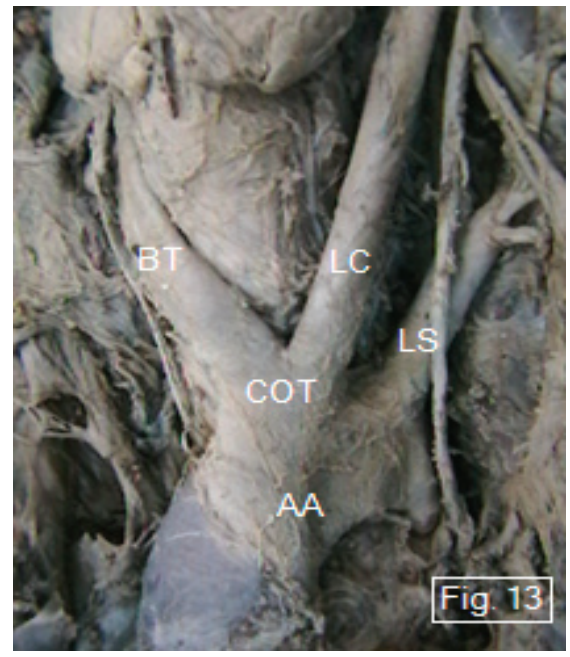

Fig. 13. A photograph of the aortic arch (AA) shows a common trunk (COT) having the shortest length between its origin from the arch and its bifurcation. BT: Brachiocephalic trunk. LC: left common carotid artery. LS: left subclavian artery.

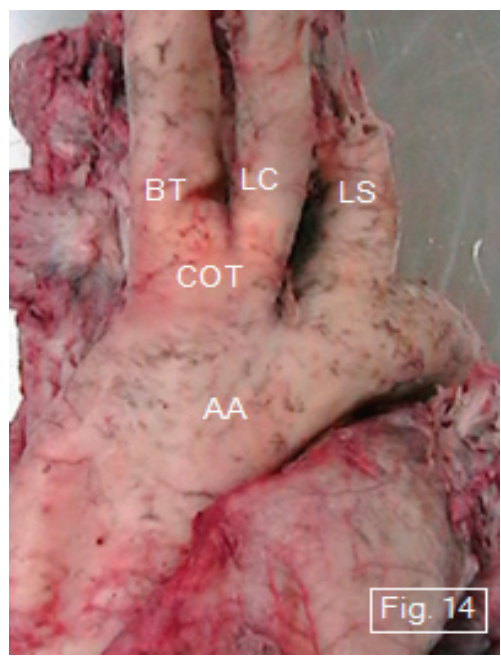

Fig. 14. A photograph of the aortic arch (AA) shows the common trunk (COT) having the smallest diameter. The brachiocephalic trunk (BT) and the left common carotid artery (LC) arise from the (COT). LS: left subclavian artery.

Table 4. Distances from mid -vertebral line, lengths of the common trunk of BT and LC and their diameters (in $\mathrm{mm}$ ).

\begin{tabular}{l|c|c|c|c|c|c}
\hline \multicolumn{1}{c|}{ Trunk } & N & Mean & SD & Minimum & Maximum & Range \\
\hline Distance from mid-vertebral line & 6 & 13.83 & -3.97 & 9.00 & 20.00 & 11.00 \\
\hline Length & 6 & 15.00 & 5.86 & 10.00 & 26.00 & 16.00 \\
\hline Diameter & 6 & 30.33 & 5.16 & 25.00 & 40.00 & 15.00 \\
\hline S
\end{tabular}

SD: standard deviation, negative (-): right side based on

In two cadavers $(22.2 \%)$ an additional artery was noted in addition to the three branches and four branches had their origin from the upper convex surface of the arch. The additional branch was traced and found to be left vertebral artery (LV). It had an independent origin from the aortic arch. It was located between the origins of the left common carotid and the left subclavian arteries. The arising sequence of the four arteries from the arch, from right to left was BT, LC, LV, and LS (Fig. 15).

The mean diameter of the LV was $5.5 \mathrm{~mm}$. (ranged from 5.00 to 6.00 $\mathrm{mm}$ ) (Fig. 15 and 16). The mean distance between the origin of the LV 
and the mid-vertebrae line, was $26.5 \mathrm{~mm}$ (ranged from 22.00 to $31.00 \mathrm{~mm})$.

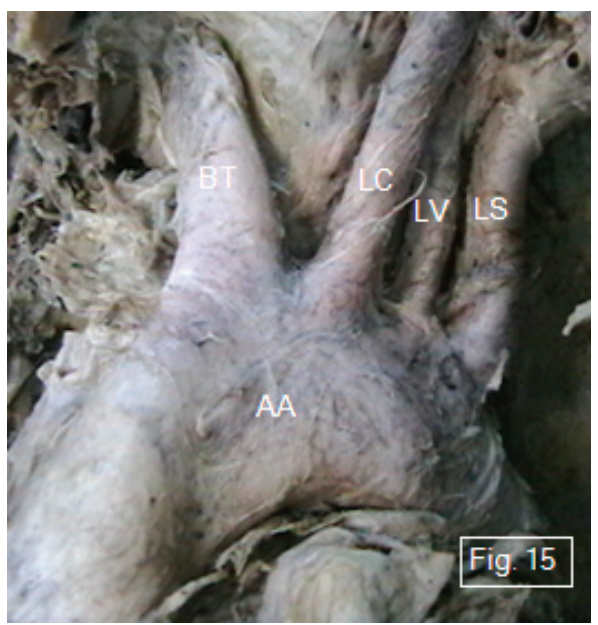

Fig. 15. A photograph of the aortic arch (AA) shows four branches arising from its upper Surface. The left vertebral artery (LV) has direct origin from the arch between the left common carotid (LC) and left subclavian arteries. BT: brachiocephalic trunk.

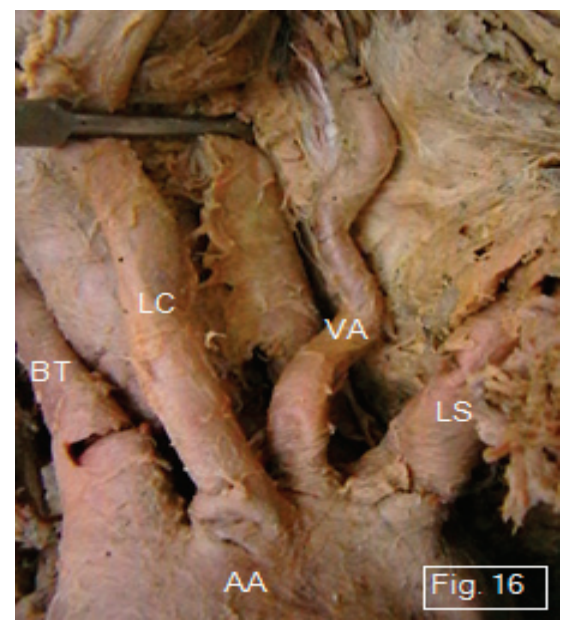

Fig. 16. A photograph of the aortic arch shows the left vertebral artery (LV) arising directly from aortic arch, between the origins of the left common carotid (LC) and left subclavian arteries (LS).

In only one cadaver (11\%) the LV arose with the LS from a common trunk. The trunk originated from the arch behind the LC. The diameter of the trunk was $20.00 \mathrm{~mm}$ (Fig. 17). The distance from its origin to the mid-vertebrae line was $31 \mathrm{~mm}$.

The cadaveric study was assisted with the computerized tomography images (Enhanced CT scan images); aortic angiography for different randomly chosen patients with different purposes. The common branching pattern of the AA in which the three major branches originated independently was observed (Fig. 18). A common origin for both the BT and the LC was also seen in some images. In such cases, the LS had an independent origin from the arch (Fig. 19). In some cases, the LV arose directly from the arch between the LC and the LS (Fig. 20). 


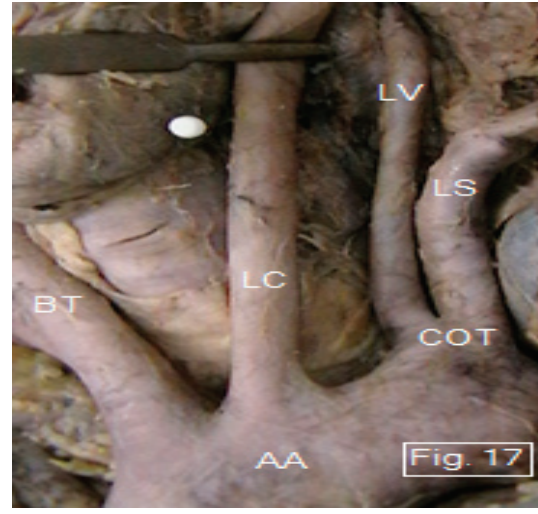

Fig. 17. A photograph of the aortic arch (AA) shows the left vertebral (LV) and the left subclavian arteries (LS) arising from a common trunk (COT). The trunk originated distal to the left common carotid artery (LC). BT: brachiocephalic trunk.

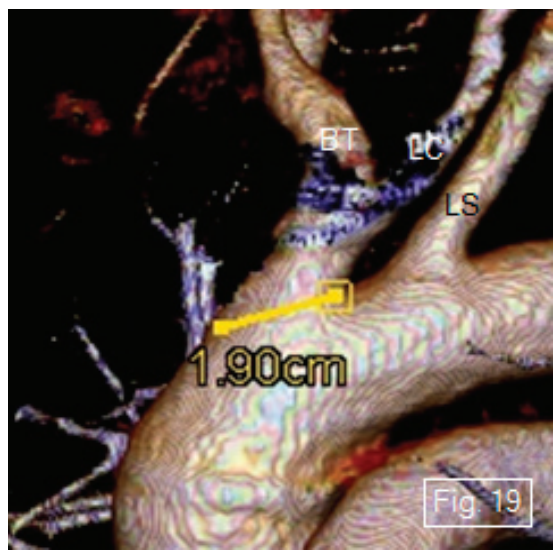

Fig. 19. A photograph of threedimensional volume-rendered CT angiogram of aortic arch (AA) showing only two arteries arising from it. The first is a common trunk (COT) of the brachiocephalic trunk (BT) and the left common carotid artery (LC). The second is the left subclavian artery (LS).

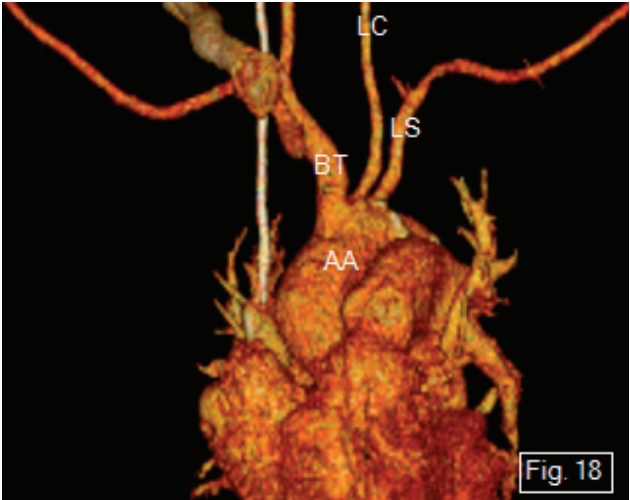

Fig.18. A photograph of three-dimensional volume-rendered $C T$ angiogram of aortic arch (AA) shows a common branching pattern. The three major branches arise independently from the arch. BT: Brachiocephalic trunk. LC: left common carotid artery. LS: left subclavian artery.

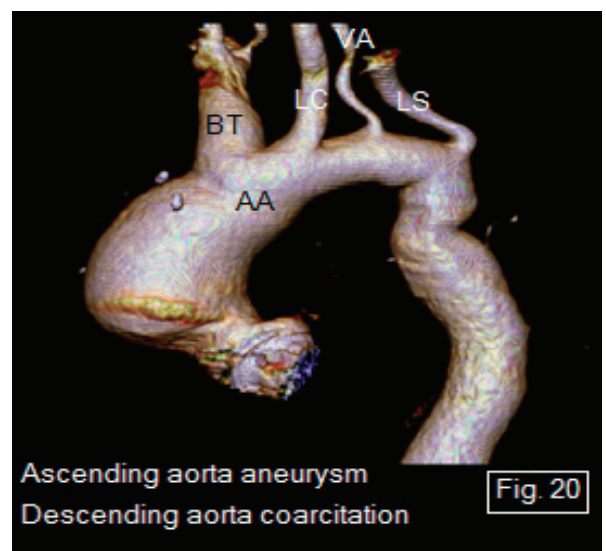

Fig. 20. A photograph of three-dimensional volume-rendered $\mathrm{CT}$ angiogram of aortic $\operatorname{arch}(\mathrm{AA})$ showing the left vertebral artery(LV) arising independently from the aortic arch between the left common carotid (LC) and the left subclavian (LS) arteries. BT: brachiocephalic trunk. 


\section{Discussion}

Detection of the anomalous origins of the branches of the AA is diagnostic before vascular surgeries of supra-aortic arteries, as their variations are likely to occur. This is attributed to the altered development of certain brachial arch arteries during the embryonic period of gestation ${ }^{[5]}$.

In the present study, the three major branches of the AA originated independently in $27(75 \%)$ cases. This finding was nearly similar to that of Lippert and Pabst where $70 \%$ of patients had this common branching pattern-. According to Lippert and Pabst ${ }^{[12]}$ this pattern was different from that found by Shin et al. ${ }^{[9]}(84 \%)$ and Paraskevas et al.$^{[13]}$ who found it in only $65 \%$.?

The current study showed that the BT originating from the branching site deviated from the right side by an average of $9.33 \pm 4.66 \mathrm{~mm}$ from the mid vertebrae line. The LC deviated by an average of $9.90 \pm 5.28$ $\mathrm{mm}$ to the left of the mid-vertebrae line, and the third branch LS deviated with an average of $25.73 \pm 7.57 \mathrm{~mm}$ to the left of the mid vertebrae line. According to Shin et al. ${ }^{[9]}$ the average distance from the origin of the BT to the mid vertebrae line was $0.92 \mathrm{~mm}$. The distance of the $\mathrm{LC}$ from the branching site to the mid vertebrae line was $12.3 \mathrm{~mm}$ and that of the LS was $22.8 \mathrm{~mm}$ to the left of the mid vertebrae line. Bhatia et al. ${ }^{[14]}$ claimed that the approximation of the LC artery to the BT is an important observation while invading the AA and its branches with instruments, since all cases are susceptible to surgical attack. Also, Gupta and Sodhi ${ }^{[15]}$ in their study on hundred cadavers found that the mean transverse distances between adjacent luminal openings of BT, LC and LS arteries were significantly greater than the mean vertical distances ( $p$ $<0.001$ ). They also observed that approximation of LC to BT trunk was seen in $10.0 \%$ specimens.

Compared to the results of Shin et al. ${ }^{[9]}$ who measured the inner diameter of the major branches at their origin from the AA and found the measurements on an average of $18.3+7.00 \mathrm{~mm}, 9.5+1.9 \mathrm{~mm}$ and $10.6+$ $2.4 \mathrm{~mm}$, for BT, LC and LS, respectively, the mean diameter of the BT, LC and LS in the present work were $17.97 \pm 3.85 \mathrm{~mm}, 9.77 \pm 1.91 \mathrm{~mm}$, and $14.33 \pm 3.09 \mathrm{~mm}$, respectively. 
In the study of six specimens (25\%), only two great vessels originated from the upper convex surface of the aortic arch. The first is a common trunk, which incorporated the BT and the LC. The second was the LS which arose independently distal to the origin of the common trunk. While Paraskevas et al. ${ }^{[13]}$ found this variation in $27 \%$ of the cases, Best and Bumpers ${ }^{[16]}$, and Beigelman et $a l^{[17]}$ found it in $8 \%$ of their studied cases. In the present study, the mean length of the trunk from its origin to the level of division into BT and the LC was $15.00 \pm$ 5.86; the mean diameter of the trunk was $30.33 \pm 5.16 \mathrm{~mm}$. The mean distance between the origin of the common trunk and the mid vertebrae line, was of $13.83 \pm 3.97 \mathrm{~mm}$.

In the present study an additional artery was noted in $2(22.2 \%)$ cadavers out of nine variations and thus, four branches had their origin from the arch. An independent separate origin of the left vertebral artery LV from the AA was identified between the LC and the LS. Shin et al ${ }^{[9]}$ found this variation in $5.8 \%$ of the cases. While Lemke et al. ${ }^{[18]}$ observed that the VA may have duplicate origin from the arch and the subclavian artery. In agreement with the present results they found that the most frequent variant $(2.4-5.8 \%)$ is the $\mathrm{LV}$, arising directly from the AA between the left common carotid artery and left subclavian artery. Paraskevas et al. ${ }^{[13]}$ also stated that the LV may arise between the left common carotid and the subclavian arteries. While Best and Bumpers ${ }^{[16]}$ reported a case in which the right vertebral artery originated directly from the aortic arch. Also, Karcaaltincaba et al.$^{[19]}$ found in eight cases that the variant of the right VA originating from the AA was distal to the left subclavian artery. Albayram et al. ${ }^{[20]}$ suggested that the aberrant origin of the LV directly from the AA is due to persistence of the $8^{\text {th }}$ intersegmental artery.

One remarkable finding in the present work was the origin of LV with the LS from a common trunk in one cadaver (11\%) out of nine variations. The trunk originated from the arch behind the LC. Its diameter was $20.00 \mathrm{~mm}$. The length from its origin to the level of division into the LV and LS was $12.00 \mathrm{~mm}$. No similar finding was reported in the current literature review.

The computerized tomography aortic angiograph images used in this study showed cases in which the BT and the LC originated from a common trunk. In some cases the AA had four independent branches in 
which the LV arose independently between the origins of the LC and the LS. The finding in the present study confirmed with that of Ka-Tak et $a l .{ }^{[21]}$ who found four branches arising from the arch in an angiographic study, but the fourth branch was an aberrant right subclavian artery that arose as the last branch and coursed posterior to the mediastinum.

On the other hand, Goray et al. ${ }^{[8]}$ found incidentally in a CT arch aortography, five branches originated directly from the AA in which an anomalous origin of both vertebral arteries originated beyond the left subclavian artery.

\section{Conclusion}

In conclusion, the different branching patterns of the AA observed in this study and the morphmetric measurements taken can assist surgeons in performing safe and effective surgeries in the superior mediastinum. Furthermore, it is recommended to search for other variations of supra aortic arteries of the neck that may accompany them.

\section{References}

[1] Mligiliche NL, Isaac ND. A three branches aortic arch variant with a bi-carotid trunk and a retro-esophageal right subclavian artery. IJAV 2009; 2: 11-14.

[2] Layton KF, Kallmes DF, Cloft HJ, Lindell EP, Cox VS. Bovine Aortic Arch Variant in Humans: Clarification of a Common Misnomer. AJNR Am J Neuroradiol 2006; 27(7): 1541-1542.

[3] Momma K, Matsuoka R, Takao A. Aortic arch anomalies associated with chromosome 22q11 deletion (CATCH 22). Pediatr Cardiol 1999; 20(2): 97-102.

[4] Suresh R, Ovchinnikov N, McRae A. Variations in the branching pattern of the aortic arch in three Trinidadians. West Indian Med J 2006; 55(5): 351-353.

[5] Nayak SR, Pai MM, Prabhu LV, D'Costa S, Shetty P. Anatomical organization of aortic arch variations in the India: embryological basis and review. J Vasc Bras 2006; 5(2): 95100.

[6] Branchereau A, Jacobs M. Complications in Vascular and Endovascular Surgery. Part 1. $1^{\text {st }}$ ed. Futura Pub Co., Inc. 2001.

[7] Suzuki K, Kazui T, Bashar AH, Yamashita K, Terada H, Washiyama N, Suzuki T. Total aortic arch replacement in patients with arch vessel anomalies. Ann Thorac Surg 2006; 81(6): 2079-2083.

[8] Goray VB, Joshi AR, Garg A, Merchant S, Yadav B, Maheshwari P. Aortic arch variation: a unique case with anomalous origin of both vertebral arteries as additional branches of the aortic arch distal to left subclavian artery. AJNR Am J Neuroradiol 2005; 26(1): 93-95.

[9] Shin Y, Chung Y, Shin W, Im S, Hwang S, Kim B. A morphometric study on cadaveric aortic arch and its major branches in 25 Korean adults: the perspective of endovascular surgery. J Korean Neurosurg Soc 2008; 44(2): 78-83. 
[10] Willinsky RA, Taylor SM, TerBrugge K, Farb RI, Tomlinson G, Montanera W. Neurologic complications of cerebral angiography: prospective analysis of 2,899 procedures and review of the literature. Radiology 2003; 227(2): 522-528.

[11] Romanes GJ, ed. Cunningham's Manual of Practical Anatomy: Vol 2: Thorax and Abdomen. 15th ed. Oxford Med Pub. 1989.

[12] Lippert H, Pabst R. Aortic arch. In: Arterial Variations in Man: Classification and Frequency. Munich, Germany: JF Bergmann-Verlag, 1985. 3-10.

[13] Paraskevas G, Agios P, Stavrakas M, Stoltidou A, Tzaveas A. Left common carotid artery arising from the brachiocephalic trunk: a case report. Cases $J$ 2008; 1(1): 83 .

[14] Bhatia K, Ghabriel MN, Henneberg M. Anatomical variations in the branches the human aortic arch: a recent study of a South Australian population. Folia Morphol (Warsz) 2005; 64(3): 217-223.

[15] Gupta M, Sodhi L. Variations in branching pattern, shape, size and relative distances of arteries arising from arch of aorta. Nepal Med Coll J 2005; 7(1): 13-17.

[16] Best IM, Bumpers HL. Anomalous origins of the right vertebral, subclavian, and common carotid arteries in a patient with a four-vessel aortic arch. Ann Vasc Surg 2002; 16(2): 231-234.

[17] Beigelman C, Mourey-Gerosa I, Gamsu G, Grenier P. :New morphologic approach to the classification of anomalies of the aortic arc . Eur Radiol 1995; 5: 435-442.

[18] Lemke AJ, Benndorf G, Liebig T, Felix R. Anomalous origin of the right vertebral artery: review of the literature and case report of right vertebral artery origin distal to the left subclavian artery. AJNR Am J Neuroradiol 1999; 20(7): 1318-1321.

[19] Karcaaltincaba M, Strottman J, Washington L. Multidetector-row CT angiographic findings in the bilateral aortic arch origin of the vertebral arteries. AJNR Am J Neuroradiol 2003; 24(1): 157.

[20] Albayram S, Gailloud P, Wasserman BA. Bilateral arch origin of the vertebral arteries. AJNR Am J Neuroradiol 2002; 23(3): 455-458.

[21] Ka-Tak W, Lam WW, Yu SC. MDCT of an aberrant right subclavian artery and of bilateral vertebral arteries with anomalous origins. AJR Am J Roentgenol 2007; 188(3): W274-275. 


\section{در اسة تشريحية للاختلافات الطبيعية لقوس الثريان الأبهر}

\section{هيفاء على الصــايف، و وفاء رمضــان'}

قسم المختبر/ت الطبية ، كلية العلوم الطبية التطبيقية، جامعة الطائف، الطائف

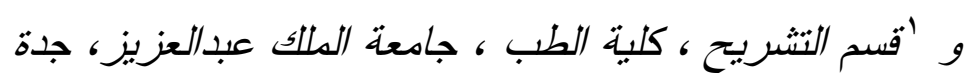

المدلكة العربية السعودية

المستخلص. للجر احات المفتوحه لقوس الثريان الأبهرمـــاعب

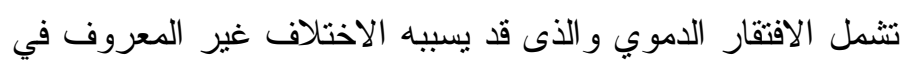

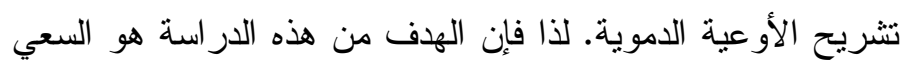

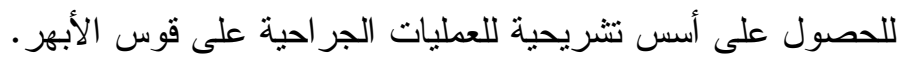

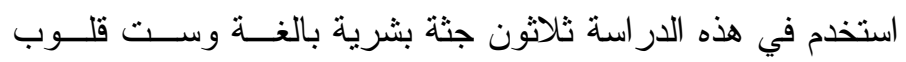

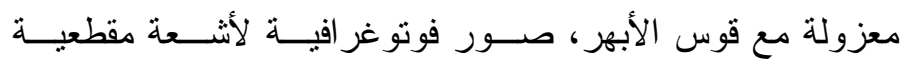

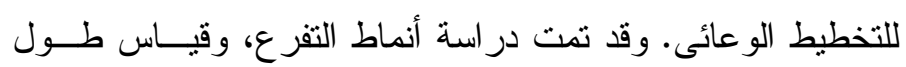

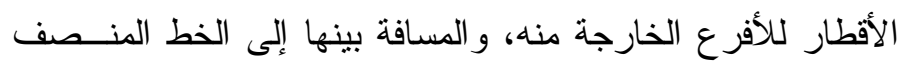

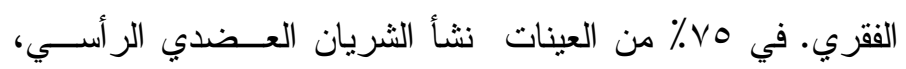
و الشريان المشترك السباتي الأيسر ، و الثريان تحت النزقوة الأيسر.

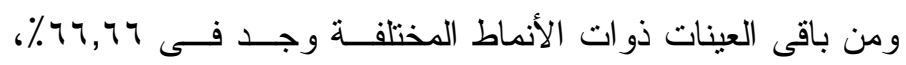
فرعان فقط، واحد يجمع بين الثريان العضدي الر أسي و الــشريان

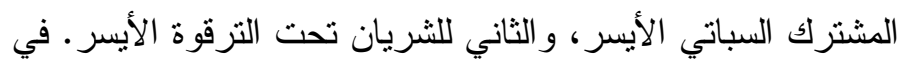

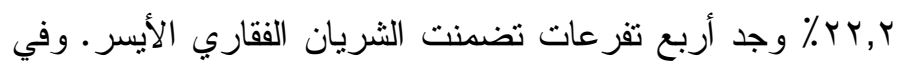
11\% من العينات اثترك الثريان الفقاري الأيسر مع الثريان تحت

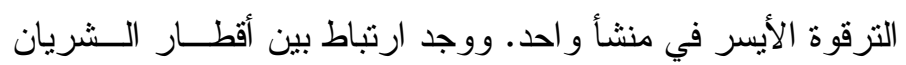

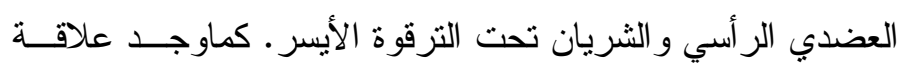
إيجابية قوية بين المسافة لكل من الثريان المشترك السباتي الأيسر لترك 


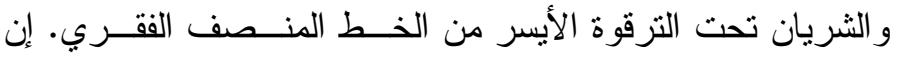
النتائج فى هذه الدراسة توفر المعلومات الدقيقة التي يمكن أن تعتبر لترن حيوية لجر احة الأوعية الدموية. 